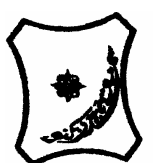

Bayero Journal of Pure and Applied Sciences, 6(2): 49 - 52

Received: April 2013

Accepted: December 2013

ISSN $2006-6996$

\title{
COMPARATIVE STUDIES ON THE MINERALIZATION OF FURFURAL UREA AND UREA FERTILIZERS IN AN ALFISOL IN SAMARU ZARIA, KADUNA STATE, NIGERIA
}

\author{
Almu, $\mathbf{H}$. \\ Department of Soil Science, Faculty of Agriculture and Agricultural Technology ,Kano University of Science and \\ Technology, P.M.B. 3244, Wudil, Kano State, Nigeria. \\ hamisu_almu@yahoo.com
}

\begin{abstract}
In this research, laboratory studies were conducted to evaluate the effects of furfural urea as a slow release $\mathbf{N}$ fertilizer in an alfisol of Nigeria Savanna in the year 2009/2010 season. Incubation studies revealed that released $\mathrm{N}$ through mineralizatoin and microbial activities had confirmed that the compound may stay longer in the soil than urea. The method used for the research is completely randomised design with three repetitions, which consists four nitrogen levels each of urea and furfural urea and an absolute control. Attention is being directed towards slow release compounds. The controlled or slow availability supplies $\mathbf{N}$ continuously over an extended period, thus, avoiding the need for repeated application of conventional water soluble fertilizers. The mineralization of both fertilizers differ, the first, and the third to the fourth week should be synchronized with demand in further studies.
\end{abstract}

Key words: Alfisol, Incubation study, furfural urea, Mineralization

INTRODUCTION

The soils of the Nigerian Guinea Savanna are predominantly Alfisol. These soils are inherently low in organic matter (OM), cation exchange capacity (CEC), deficient in Nitrogen $(\mathrm{N})$ and phosphorus $(\mathrm{P})$ and are largely coarse textured. This low level of OM has made the Savanna soil susceptible to major chemical, physical and biological limitations which reduce crop yields (Jone and Wild, 1993). The soils are exposed to true high temperature and rainfall concentrated over a period of five months of the year. The prolonged use of chemical fertilizers especially $\mathrm{N}$ fertilizers gives rise to residual soil acidity and cation depletion (Jones, 1989, Bache and Heathcote, 1988). Under intensive agriculture now commonly practiced, soil fertility declines rapidly after a few years of continuous cultivation. The use of external input fertilizer amendments is therefore a pre-requisite to increasing and maintaining crop yields to feed the teaming population (Lombin, 1988).

The overall objective of research in the use of nitrogenous fertilizer is to maximize the efficiency of plant use of applied nitrogen. This will determine the agronomic and economic value of fertilizer. It will also conserve energy and raw material needed to make the $\mathrm{N}$ fertilizer and minimize possible adverse effects on the environment (nitrate pollutants) that may result from the inefficient $\mathrm{N}$ use (Bremer and Hauk, 1988). The soils are generally deficient in nitrogen (Mokwunye and Vlek, 1988). Under this situation the only feasible way of maintaining the fertility of these inherently poor soils is through the use of fertilizers. Among the commercial $\mathrm{N}$ fertilizer, urea in the most widely used, because of its low unit cost per nitrogen (Lombin, 1988).

Urea is readily hydrolyzed in water and the $\mathrm{NH}_{4}{ }^{+}$and $\mathrm{NO}_{3}$ are readily released for plant uptake. Factors affecting these process include, supply of $\mathrm{NH}_{4}^{+} \mathrm{ic}^{n-}$ population of nitrifying organisms, soil $\mathrm{pH}$, aeration, moisture and temperature The $\mathrm{NH}_{4}{ }^{+}-\mathrm{N}$ in immobile soil and in theoretically utilized more efficiently within the plant and is less subjected to loss by leaching from the soil ( Barber, 1982 ).Although crop yield can be obtained with judicious fertilizer use, the use of slow released fertilizer may be more efficient (furfural urea ). Nitrogen mineralization is the process by which organic $\mathrm{N}$ is converted to plant available inorganic forms. Nitrogen $(\mathrm{N})$ comes in both organic and inorganic forms. Inorganic $\mathrm{N}$, mostly ammonium $\left(\mathrm{NH}{ }_{4}^{+}\right.$) and nitrate $\left(\mathrm{NO}_{3}\right)$, is readily available to plants. Before organic $\mathrm{N}$ can be taken up, however, it must first be converted to inorganic forms. This process, which is completed by soil microbes as a byproduct of organic matter decomposition, is called mineralization (Gilmour et al., 2003). The mineralization rate is therefore, the rate at which organic $\mathrm{N}$ is made plant available. An understanding of the mineralization rate concept can help improve manure management to meet crop $\mathrm{N}$ demands while minimizing the potential regulatory concerns regarding groundwater pollution ( Myrold, 2008). The aims of the research is to determine the best form of fertilizer (furfural urea or urea ) that releases $\mathrm{N}$ through mineralization and to improved manure management to meet crop demands.

\section{MATERIALS AND METHODS \\ Incubation Study}

The soil sample for the incubation study was collected from Institute of Agricultural Research (IAR) farm, behind National Agricultural Extension Research and Liaison Services (NAERLS). Soil samples used in the study were collected from a plot in the long-term fertilizer and manure trials where no fertilizer has been used for the past 60 years. 
The samples were taken using hoe at $0-15 \mathrm{~cm}$ depth only. Samples were also taken from fallow plots where no cultivation has been carried out for many years in the long-term fertilizer and manure trials. The composite samples were air dried, crushed and sieved through a $2 \mathrm{~mm}$ mesh sieve after removal of foreign materials. Nine plastic pots with lids of about 1 litre capacity were used for the incubation study. Into each of the plastic pots was weighed $2.5 \mathrm{~kg}$ of the soil sample. The amounts of urea and furfural urea weighed out were 0.57., 1.15, 1.73, 2.5 and 0.23, $0.45,0.68$ and $0.9 \mathrm{mg}$ respectively. They were put in to the appropriate plastic pots for the incubation study. These amounts correspond to application rates of $50,100,150$ and $200 \mathrm{kgN} / \mathrm{ha}$ respectively.

The plastic pots containing the treated soil sample and the control without fertilizers were kept in temperature cabinets maintained at room temperature (about $25^{\circ} \mathrm{C}$ to $30^{\circ} \mathrm{C}$ ). The moisture was maintained at near field capacity throughout the period ensuring that the pots were not dried completely. Water logging condition was also avoided. The plastic pots were opened periodically to ensure proper aeration and the moisture content was also maintained by adding water once a week. The design was completely randomized with three repetitions. The $\mathrm{NH}_{4}-\mathrm{N}$ and $\mathrm{NO}_{3}-\mathrm{N}$ released from furfural urea and urea after one week of incubation period were monitored. The recovery of inorganic $\mathrm{N}$ in the form of $\mathrm{NH}_{4}-\mathrm{N}$ and $\mathrm{NO}_{3}-\mathrm{N}$ mineralized at interval of six weeks were determined as follows:

a) $\mathrm{NH}_{4}-\mathrm{N}$ : Ten centimeter of $2 \%$ Boric acid $\left(\mathrm{H}_{3} \mathrm{BO}_{3}\right)$ solution and 2 drops of mixed indicator solution were added to a $50 \mathrm{~cm}^{3}$ Erlenmeyer flask which was placed under the condenser to steam distiller. The end of the condenser was about $1 \mathrm{~cm}$ below the surface of $\mathrm{H}_{3} \mathrm{BO}_{3}$ solution. $2.0 \mathrm{~g}$ of the sample was put into a distillation flask; $0.5 \mathrm{~g}$ of $\mathrm{MgO}$ was added. The extract was distilled into $\mathrm{H}_{3} \mathrm{BO}_{3}$ solution until about $30-50 \mathrm{~cm}^{3}$ of the distillate was collected in the receiver flask. The amount of $\mathrm{NH}_{4}-\mathrm{N}$ in the distillate was determined by filtration with $0.02 \mathrm{~m} \mathrm{H}_{2} \mathrm{SO}_{4}$. The colour change at end point was from green to pink.

b) $\mathrm{NO}_{3} \mathrm{~N}$ : To the same extract used for the $\mathrm{NH}_{4}-\mathrm{N}$ distillation, $0.2 \mathrm{~g}$ of Devarda's alloy was added. Distillation was carried out over another $10 \mathrm{~cm}^{3}$ of $2 \% \mathrm{H}_{3} \mathrm{BO}_{3}$ solution which contained 2 drops of the mixed indicator. The distillate was again titrated against $0.02 \mathrm{~m}$ $\mathrm{H}_{2} \mathrm{SO}_{4}$ to end point. The distillate was again titrated against $0.02 \mathrm{~m} \mathrm{H}_{2} \mathrm{SO}_{4}$ to end point. The $\mathrm{NH}_{4}-\mathrm{N}$ and $\mathrm{NO}_{3}-\mathrm{N}$ were calculated using the formula below:

\% $\mathrm{NH}_{4}-\mathrm{N} / \mathrm{NO}_{3}-\mathrm{N}=$
$\mathrm{T}=$ titre value
$\mathrm{B}=$ Blank

\section{Data Analysis}

The data collected were analysed statistically to determine the treatment effect for significance using the F-test while the difference in treatment means was separated using Duncan Multiple Range test ( DMRT ) for those that were significant(Duncan, 1995).

\section{RESULTS AND DISCUSSION Mineralization study \\ $\mathrm{NH}_{4}{ }^{+}-\mathrm{N}$ released from furfural urea and urea during the studies. \\ The $\mathrm{NH}_{4}{ }^{+}-\mathrm{N}$ released from furfural urea and urea after} sixth weeks of incubation is shown in Table 1 . Where urea was applied at $150 \mathrm{~kg} \mathrm{~N} / \mathrm{ha}, \mathrm{NH}_{4}^{+}-\mathrm{N}$ released was highest at first week of incubation. After the second weeks of incubation, $\mathrm{NH}_{4}{ }^{+}-\mathrm{N}$ released was still the highest where urea was applied at $150 \mathrm{Kg} / \mathrm{N}$. However, there was no release of $\mathrm{NH}_{4}-\mathrm{N}$ in the absolute control treatments. After the third and fourth weeks of incubation $\mathrm{NH}_{4}-\mathrm{N}$ released in furfural urea were significantly the same at all rates of application. However, for $\mathrm{NH}_{4}-\mathrm{N}$ mineralised in urea increased with increase in urea rate of application. The results of $\mathrm{NH}_{4}-\mathrm{N}$ released from furfural urea and urea at the fifth and sixth weeks were the same.

\section{$\mathrm{NO}_{3}-\mathrm{N}$ released from furfural urea and urea during the studies}

The $\mathrm{NO}_{3}{ }^{-} \mathrm{N}$ released from furfural urea and urea after six weeks of incubation is shown in table 2. The release of $\mathrm{NO}_{3}{ }^{-} \mathrm{N}$ in urea is highest at $150 \mathrm{~kg} / \mathrm{N}$ at the first week of incubation. This was followed by treatment $50 \mathrm{~kg} / \mathrm{N}$ urea. It could be seen that the significance is almost the same in $\mathrm{NO}_{3}{ }^{-} \mathrm{N}$ at all weeks of incubation by furfural urea and urea. For both $\mathrm{NH}_{4}^{-}$ $\mathrm{N}$ and $\mathrm{NO}_{3}-\mathrm{N}$ mineralised dropped from the peak observed at the first and second week of incubation. However, mineralization rates of $\mathrm{NH}_{4}-\mathrm{N}$ and $\mathrm{NO}_{3}-\mathrm{N}$ decreased at all weeks of incubation.

The release of $\mathrm{NH}_{4}{ }^{+}$and $\mathrm{NO}_{3}^{-}$in the soil may guarantee plant $\mathrm{N}$ use efficiency (Rosliza, 2009).

With attention being directed towards slow release compounds, the controlled or slow availability supplies $\mathrm{N}$ continuously over an extended period, thus avoiding the need for repeated application of conventional water- soluble fertilizers. They also reduce $\mathrm{N}$ lose and reduce the hazard of seedling injury from over population (Allen et al., 1991; Beaton et al., 1987). 
The hydroscopic nature of furfural urea than urea increases its tendencies to bind together and reduces its free flow rate The quantity of $\mathrm{N}$ in the soils is intimately associated with organic matter levels in the soils, and since the soil used for the trial has low organic matter, these explained no traces of $\mathrm{NH}_{4}-\mathrm{N}$ in the soil. The absence of organic matter and inherent inorganic $\mathrm{N}$ in the will limit crop growth and yield of crops.

Table 1: $\mathrm{NH}_{4}-\mathrm{N}$ Released from furfural urea and urea according to weeks

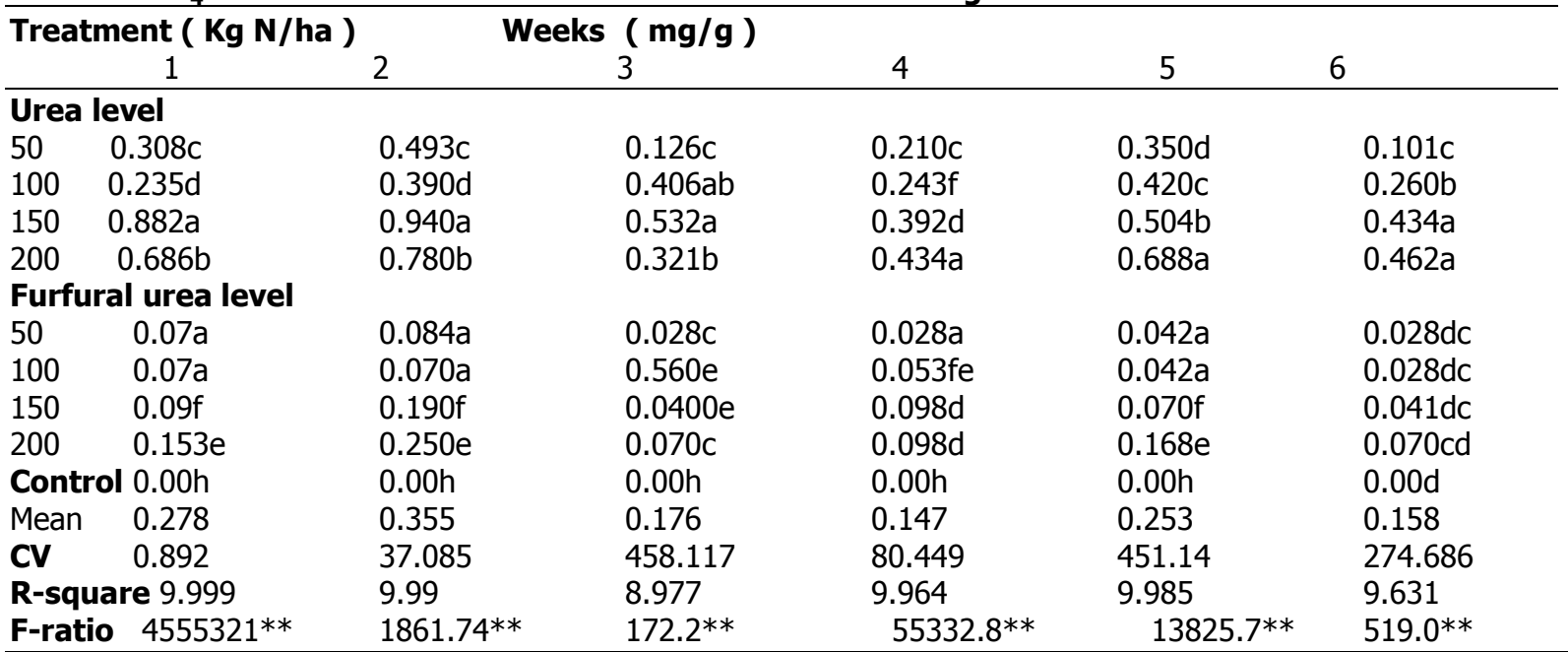

Means with the same letter (s) within the same column are not significantly different at five percent of significance using DMRT.

Table 2: $\mathrm{NO}_{3}-\mathrm{N}$ Released from furfural urea according to weeks

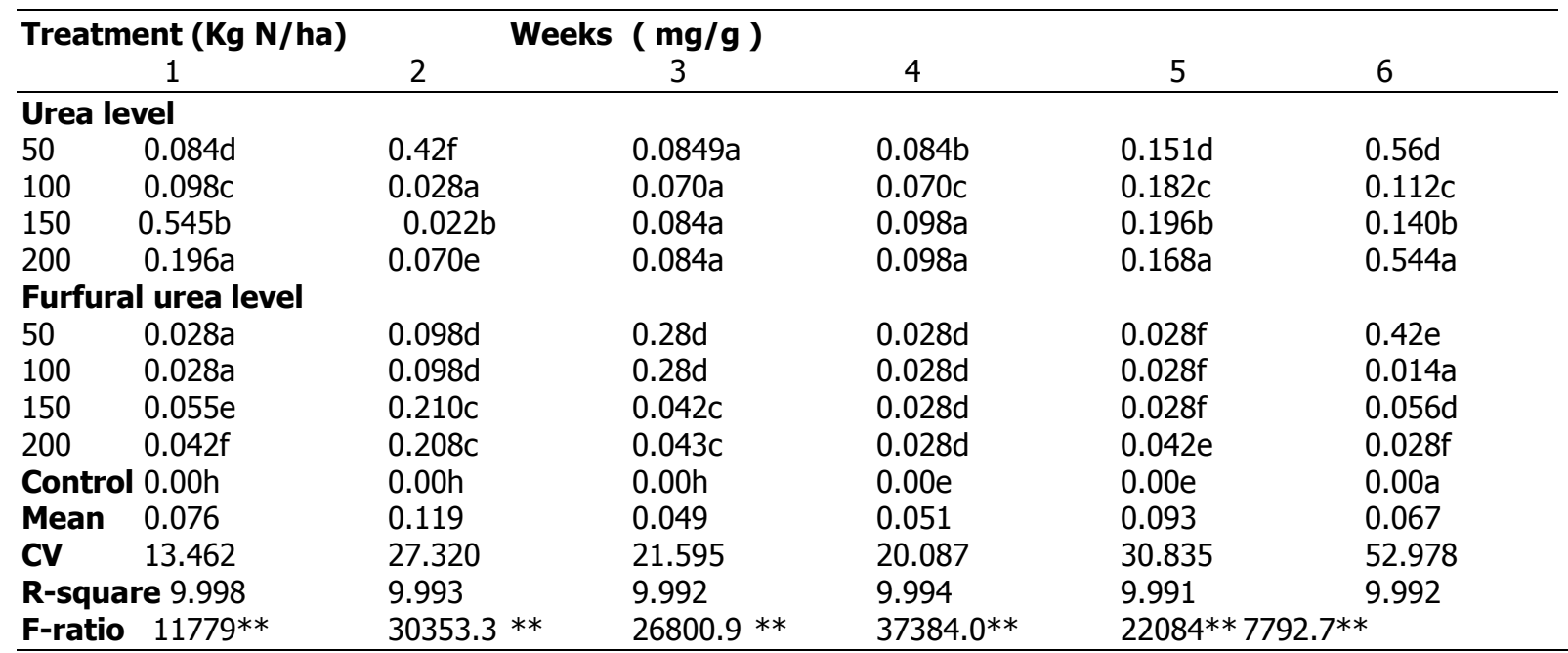

Means with the same letter (s) within the same column are not significantly different at five percent level of significant using DMRT.

\section{CONCLUSION}

In the mineralization study, it was noted that the Furfural urea and Urea release inorganic nitrogen to the soil. The release $\mathrm{NH}_{4}{ }^{+}$and $\mathrm{NO}_{3}$ in the soil guarantee plant uptake nitrogen use efficiency. The furfural urea release $\mathrm{NH}_{4}{ }^{+}-\mathrm{N}$ slowly compared to urea guaranteeing longer supply of $\mathrm{N}$ than urea. The mineralization of furfural urea and urea differs. The mineralization of both fertilizers reached their peak in the first week and latter dropped. The mineralization rate pick up again at the third and fourth weeks. The first and second weeks should be synchronized with crop demand in further studies. The mineralization rate is therefore the rate at which organic $\mathrm{N}$ is made plant available.

\section{Recommendation}

Base on the research findings it is found out that furfural urea releases $\mathrm{N}$ slowly compared to urea fertilizer, so govt through agricultural policies should make sure that furfural urea is made available to farmers to avoid repeated application of conventional water soluble fertilizers. 


\section{REFERENCES}

Agbenin, J.O (1995 ): Laboratory Manual for Soil and Plant Analysis (selected methods and data analysis).Dept. of Soil Science, Fac. Agric/IAR A.B.U Zaria.

Allen, S.E., Termon, G.L. and Hunt, CM. (1991). Soluble and slow release nitrogen fertilizer effects on grass forage as influenced by rate and placement. J. Agric. Sc. Comb. 77: 397 447.

Bache, B.W. and Heathcote, RG. (1988): Long term effect of fertilizers and manures on soils and leaves of cotton in Nigeria. Expt. Agric. 5: 241-247.

Barber, S.A. (1982). A diffusion and mass concept of soil nutrient availability. Soil Sci. 93: 39-49.

Beaton, J.D., Hubbard, W.A. and Spear, RC (1987): Coated urea, thiourea, ureaformaldehyde, hexamine, oxamide, glycoluril and oxidized nitrogen enriched coal as slowly available sources of nitrogen for orchard grass. Agron. J. 59: 127-133.

Bremner, J.M. and Hauck, RD. (1988 ): Perspectives in soil fertilizer nitrogen research. International Congr. Soil Sci. Trans. 10th (Moscow) 9: 1327.

Duncan, D.B. (1995). Multiple range and multiple ftest. Biometric. 11: 1-2.

Gilmour, J.T., Cogger, C.G. Jacobs, L.W Evanylo,G.K., Suillivan, D.M (2003): 'Decomposition plant available nitrogen in biosolids: laboratory studies, field studies and computersimulation.' J. Environ. Qual. 32: 1498-1507.

Jones, M.J. (1989): New recommendations for nitrogen fertilizers in northern States. Samaru, Agric, News. 16:67-73.

Jones, M.J. and Wild, A. (1993) : Soils of the West African savanna. Commonwealth Agricultural Bureau, Commonwealth Bureau of Soils Technical Comm. No. 55 Harpenden, England

Lombin, G. (1988): Agronomic management of nitrogen fertilizers in the semiarid savanna for enhancing their $\mathrm{N}$-supplying efficiency. A paper presented at the International symposium on scrub Savanna studies held at Abubakar Tafawa Balewa University, Bauchi, Nigeria. February, 1988.
Mokwunye, A. and Vlek (1988): The role of inorganic fertilizers in the cheh1ical degradation of Nigeria savanna soils. Samaru Conf. Paper No. 14: 41-63.

Myrold, D.D. (2008): Microbial nitrogen transformations. P. 259-294. In principles and application of Soil Microbiology (D.M. Sylvia, J.J. Fuhrmann, P.G. Hartel, and D.A Zuberer, eds). Pretice Hall, Upper Saddle River, NJ.

Rosliza, S., Ahmad, O.H., Majid, H.M (2009): Controlling Ammonia Volatilization by mixing urea with Humic urea Acid, Triple SUpeiphosphate and Muriate of potash, American Journal of Environmental Sciences 5(9):605-609. 